\title{
Dynamics of subdural hygroma following decompressive craniectomy: a comparative study
}

\author{
Bizhan Aarabi, M.D., F.R.C.S.C., ${ }^{1}$ David Chesler, M.D., Ph.D., ${ }^{1}$ \\ Christopher Maulucci, M.D., ${ }^{1}$ Tiffany Blacklock, C.R.N.P., ${ }^{2}$ \\ and Melvin Alexander, M.S.P.H. \\ ${ }^{1}$ Department of Neurosurgery and ${ }^{2} R$ Adams Cowley Shock Trauma Center, \\ University of Maryland School of Medicine, Baltimore, Maryland
}

Object. This retrospective comparative cohort study was aimed at discovering the risk factors associated with subdural hygroma (SDG) following decompressive craniectomy (DC) to relieve intracranial hypertension in severe head injury.

Methods. Sixty-eight of 104 patients who had undergone DC during a 48-month period and survived $>30$ days were eligible for this study. To assess the dynamics of subdural fluid collections, the authors compared CT scanning data from and the characteristics of 39 patients who had SDGs with the data in 29 patients who did not have hygromas. Variables significant in the appearance, evolution, and resolution of this complication were analyzed in a 36-week longitudinal study.

Results. The earliest imaging evidence of SDG was seen during the 1st week after DC. The SDG volume peaked between Weeks 3 and 4 post-DC and was gradually resolved by the 17th week. Among the mechanisms of injury, motor vehicle accidents were most often linked to the development of an SDG after DC ( $<<0.0007)$, and falls were least often associated $(\mathrm{p}<0.005)$. Moreover, patients with diffuse brain injury were more prone to this complication $(\mathrm{p}<0.0299)$ than those with an evacuated mass $(\mathrm{p}<0.0001)$. There were no statistically significant differences between patients with and without hygromas in terms of age, sex, Glasgow Coma Scale score, intraventricular and subarachnoid hemorrhage, levels of intracranial pressure and cerebral perfusion pressure, timing of decompression, and the need for CSF diversion. More than $90 \%$ of the SDGs were ipsilateral to the side of the craniectomy, and 3 (8\%) of 39 SDGs showed evidence of internal bleeding at $\sim 8$ weeks postinjury. Surgical evacuation was needed in 4 patients with SDGs.

Conclusions. High dynamic accidents and patients with diffuse injury were more prone to SDGs. Close to $8 \%$ of SDGs converted themselves into subdural hematomas at $\sim 2$ months postinjury. Although SDGs developed in 39 $(\sim 60 \%)$ of 68 post-DC patients, surgical evacuation was needed in only 4. (DOI: 10.3171/2009.3.FOCUS0947)

\section{Key WoRds • decompressive craniectomy • subdural hygroma • head injury $\quad$ intracranial pressure}

A UTOPSY verification of subdural fluid collections following severe head injury was first documented in 1733 by Professor Thomas Schwencke. ${ }^{20}$ In 1894 Mayo cared for a 12-year-old boy suffering from headache, dysphasia, and right hemiparesis following trauma. ${ }^{15}$ Trephination of the skull on the left side revealed a liquid similar to CSF, whose evacuation relieved the symptoms and led to functional recovery. ${ }^{9,15}$ In 1924 Naffziger ${ }^{49}$ discovered a tear in the arachnoid membrane,

\footnotetext{
Abbreviations used in this paper: ATP = adenosine- $5^{\prime}-$ triphosphate; $\mathrm{CPP}=$ cerebral perfusion pressure; $\mathrm{DC}=$ decompressive craniectomy; GCS = Glasgow Coma Scale; GOS = Glasgow Outcome Scale; ICP = intracranial pressure; $\mathrm{MVA}=$ motor vehicle accident; SDG = subdural hygroma; SDH = subdural hematoma.
}

permitting egress of the CSF into the subdural space, which would then become a mass. In 1945 Walter Dandy ${ }^{16,17}$ coined the term "subdural hygroma" for a benign collection of CSF in the subdural space. In the 1980s, after the introduction of CT, SDGs became the subject of intense imaging investigations. . $, 6,15,22,28,33,64,65$ Detailed electron microscopy studies of the arachnoid-dura interface by Haines et al ${ }^{25}$ and Schachenmayr and Friede ${ }^{63}$ combined with documentation of CSF collections in the subdural space on contrast cisternography have helped us to better understand the pathogenesis of SDGs. ${ }^{27,46}$ The inflammatory response in the SDG cavity, as indicated by cytokine activation, results in neomembrane formation rich in porous and fragile capillaries. The rupture of these capillaries, together with stress-induced tearing of 
B. Aarabi et al.

TABLE 1: Summary of characteristics in 68 patients with or without SDG following DC for severe head injury*

\begin{tabular}{|c|c|c|c|c|}
\hline \multirow[b]{2}{*}{ Variable } & \multicolumn{3}{|c|}{ №. $(\%)$} & \multirow[b]{2}{*}{ p Value } \\
\hline & Total & w/ SDG & w/o SDG & \\
\hline no. of patients & 68 & 39 & 29 & \\
\hline male sex & $50(73.5)$ & $27(69.2)$ & $23(79)$ & NS \\
\hline mean age (yrs) & 27.8 & 24.9 & 29 & NS \\
\hline \multicolumn{5}{|l|}{ mechanism of injury } \\
\hline MVA & $45(66)$ & $31(79.5)$ & $14(48.3)$ & 0.0007 \\
\hline fall & $13(19)$ & $3(7.7)$ & $10(34.5)$ & 0.005 \\
\hline assault & $7(10.3)$ & $3(7.7)$ & $4(13.8)$ & NS \\
\hline other & $3(4.4)$ & $2(5.1)$ & $1(3.4)$ & NS \\
\hline \multicolumn{5}{|l|}{ clinical characteristics } \\
\hline mean admission GCS score & 6.8 & 6.8 & 6.9 & NS \\
\hline mean admission GCS motor score & 4.1 & 4.2 & 4 & NS \\
\hline patients w/APR & 21 & 11 & 10 & NS \\
\hline mean injury severity score & 30.5 & 31.4 & 29 & NS \\
\hline \multicolumn{5}{|l|}{ injury severity (no. of patients w/) } \\
\hline$>5-\mathrm{mm}$ shift on CT & $29(42.6)$ & $14(35.9)$ & $15(51.7)$ & 0.1918 \\
\hline compressed or obliterated BCs & $53(77.9)$ & $33(84.6)$ & $20(69)$ & 0.1253 \\
\hline intraventricular hematoma & $21(30.9)$ & $13(33.3)$ & $8(27.6)$ & 0.6108 \\
\hline subarachnoid hemorrhage & $45(66.2)$ & $24(61.5)$ & $21(72.4)$ & 0.3458 \\
\hline diffuse injury & $45(66.2)$ & $30(76.9)$ & $15(51.7)$ & 0.0299 \\
\hline evacuated mass & $23(33.8)$ & $9(23.1)$ & $24(82.8)$ & 0.0001 \\
\hline \multicolumn{5}{|l|}{ treatment } \\
\hline patients w/ early surgery $\dagger$ & $31(45.6)$ & $16(41)$ & $15(52)$ & 0.3810 \\
\hline patients $\mathrm{w} /$ delayed surgery $\neq$ & $37(54.4)$ & $23(59)$ & $14(48)$ & 0.3810 \\
\hline ICP before DC $(\mathrm{mm} \mathrm{Hg})$ & 22.6 & 22.2 & 23.1 & NS \\
\hline ICP after DC (mm Hg) & 13.9 & 13.6 & 14.3 & NS \\
\hline CPP before DC (mm Hg) & 69 & 68 & 69 & NS \\
\hline CPP after DC (mm Hg) & 74.6 & 75 & 74 & NS \\
\hline patients needing CSF diversion & 13 & $6(46) \S$ & $7(54) \S$ & NS \\
\hline \multicolumn{5}{|l|}{ GOS score } \\
\hline $1-3$ & $30(44)$ & $15(50)$ & $15(50)$ & NS \\
\hline $4-5$ & $38(55.9)$ & $24(63)$ & $14(37)$ & 0.2760 \\
\hline
\end{tabular}

parasagittal veins, converts a benign-looking SDG into a potentially problematic chronic SDH. ${ }^{19,21,37,48,55,56}$ In the studies by Koizumi et al. ${ }^{37}$ and St John and Dila, ${ }^{64} 32$ of 63 SDGs were bilateral, 12 were on the right side, and 19 were on the left side, indicating no predilection for any particular side of the brain.

In recent years, DC has been used more often as a means of reducing intracranial hypertension unresponsive to maximum medical treatment. ${ }^{1,2,10,11,23,29,47,58,68,70,74}$ Selecting DC as a second-tier option in the management of severe head injury mandates attention to a frequent complication of this operative procedure, namely the SDG. ${ }^{1,2,34,41,76}$

In this investigation, we studied the clinical and imaging characteristics of 39 patients with SDGs and compared them with those of 29 patients without to better understand the dynamics of the initial appearance, increase

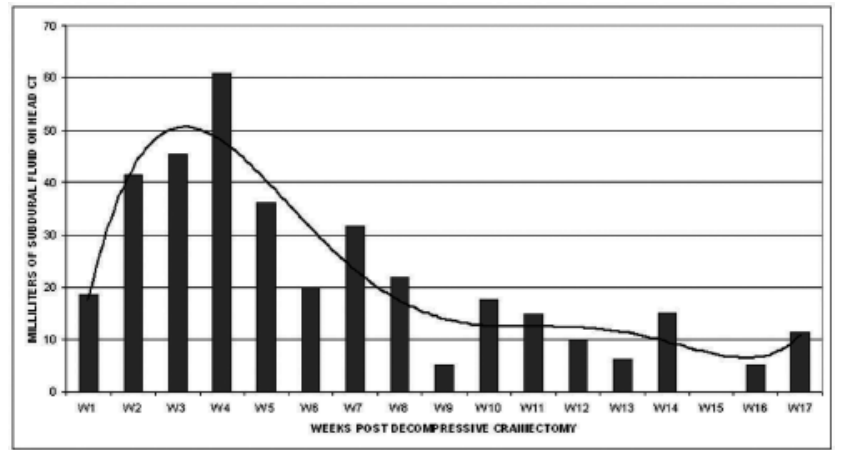

FIG. 1. Graph depicting volumetric CT evidence of an SDG after DC in 39 patients whose course of recovery was complicated by a hygroma. Fluid collection in the subdural space started from Week 1 postDC, peaked at Week 4 , and gradually declined and disappeared around Week 17. The volume of each SDG was calculated using the methods of Gebel et al. and Sucu et al. W = week. 


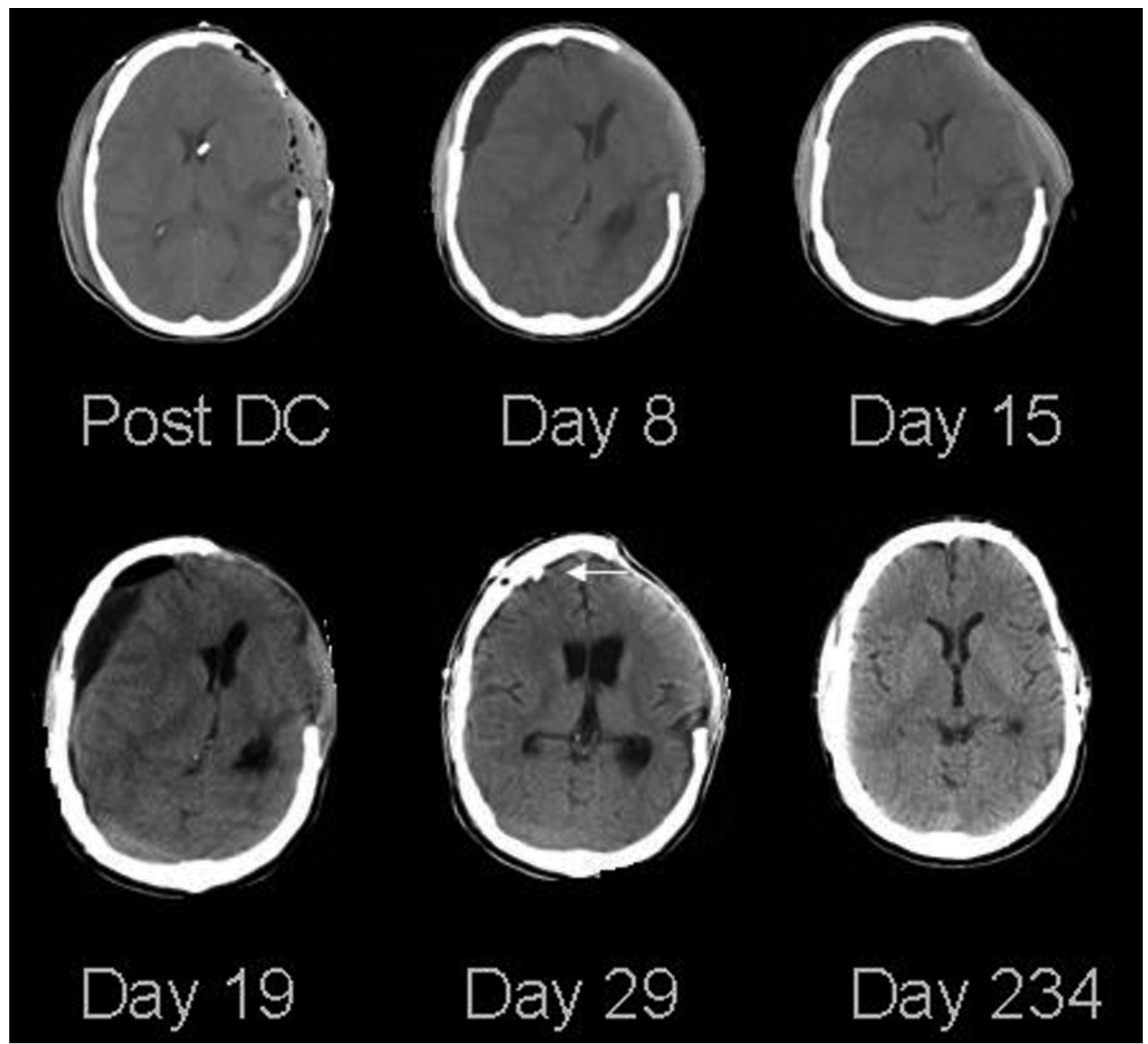

FIG. 2. Noncontrast head CT scans obtained from a 24-year-old man who had been in an MVA for which he underwent DC in April 2000. His admission GCS score was 11 and the Injury Severity Score was 29. On Day 4 of his admission, he had to undergo urgent exploration because of neurological worsening. His postoperative clinical course was uneventful; however, on Day 8 after DC he underwent another CT study because of a decline in his mental status; the CT scan indicated evidence of an SDG with significant shift of the midline structures to the left. He underwent 2 attempts to evacuate the SDG by the insertion of a drainage system through a twist drill bur hole at bedside in the intensive care unit (arrow, Day 29). Eight months after the DC, he had an autologous cranioplasty. He remained neurologically intact 47 months after discharge from the institution.

in volume, and resolution of this seemingly benign-looking complication following DC. ${ }^{1-3,66,76,77}$

\section{Methods}

The institutional review board of the University of Maryland School of Medicine approved this study.

\section{Patient Population}

During a 48-month period between March 2000 and March 2004, 104 of 967 patients with severe head injury underwent DC. The clinical characteristics as well as the prehospital, initial medical, maximum medical, and surgical treatments in these patients have been reported elsewhere. ${ }^{2,3}$ Included in the present analysis were 39 patients in whom an SDG developed postoperatively and 29 patients without an SDG. Excluded were those patients who died shortly after DC (36 patients). Demographics, clinical and imaging profiles, and outcomes in these 2 groups of patients are listed in Table 1 .

\section{Timeline of SDG Evolution}

We monitored the postoperative head CTs of the 
TABLE 2: Composition of subdural fluid in 5 patients with SDGs

\begin{tabular}{ccccc}
\hline $\begin{array}{c}\text { Case } \\
\text { No. }\end{array}$ & $\begin{array}{c}\text { Red Blood } \\
\text { Cells }\left(/ \mathrm{mm}^{3}\right)\end{array}$ & $\begin{array}{c}\text { White Blood } \\
\text { Cells }\left(/ \mathrm{mm}^{3}\right)\end{array}$ & $\begin{array}{c}\text { Protein } \\
(\mathrm{mg} / \mathrm{dl})\end{array}$ & $\begin{array}{c}\text { Glucose } \\
(\mathrm{mg} / \mathrm{dl})\end{array}$ \\
\hline 1 & 40,000 & 726 & 408 & 48 \\
2 & 22,000 & 17 & 556 & 78 \\
3 & 13,000 & 55 & 246 & 88 \\
4 & 8,950 & 50 & 118 & 61 \\
5 & 1,990 & 17 & 60 & 100 \\
\hline
\end{tabular}

group with SDGs for 36 weeks and measured the volume of hygroma fluid using the methods of Gebel et al. ${ }^{24}$ and Sucu et al. ${ }^{67}$ The mean volume of SDG fluid was $\sim 10 \mathrm{ml}$ during the 1st week, rose to $60 \mathrm{ml}$ during the 4th week, and then gradually decreased and ultimately disappeared around the 17 th week post-DC (Fig. 1).

\section{Lateralization of SDGs}

Thirty-six (92\%) of 39 SDGs were ipsilateral to the site of DC and 3 were contralateral. Significant shifts of the midline structures were noticed in $1(2.8 \%)$ of the 36 patients with an ipsilateral SDG and in $2(67 \%)$ of 3 patients with contralateral hygromas (Fig. 2).

\section{Hydrocephalus With or Without SDG}

Six $(15 \%)$ of 39 patients with SDGs had evidence of hydrocephalus during Weeks 5-8, 17, and 22 post-DC and underwent placement of a shunting device (Fig. 3). In 4 of these patients autologous cranioplasty was performed 1, 2, 5, and 26 days after CSF diversion, and in 2 patients a shunting device was inserted 35 and 155 days after cranioplasty for late-onset hydrocephalus. Among the patients without SDGs, hydrocephalus developed in 7 (24\%). Criteria for the diagnosis of hydrocephalus were CT evidence of dilation of the temporal horn tips, globu-

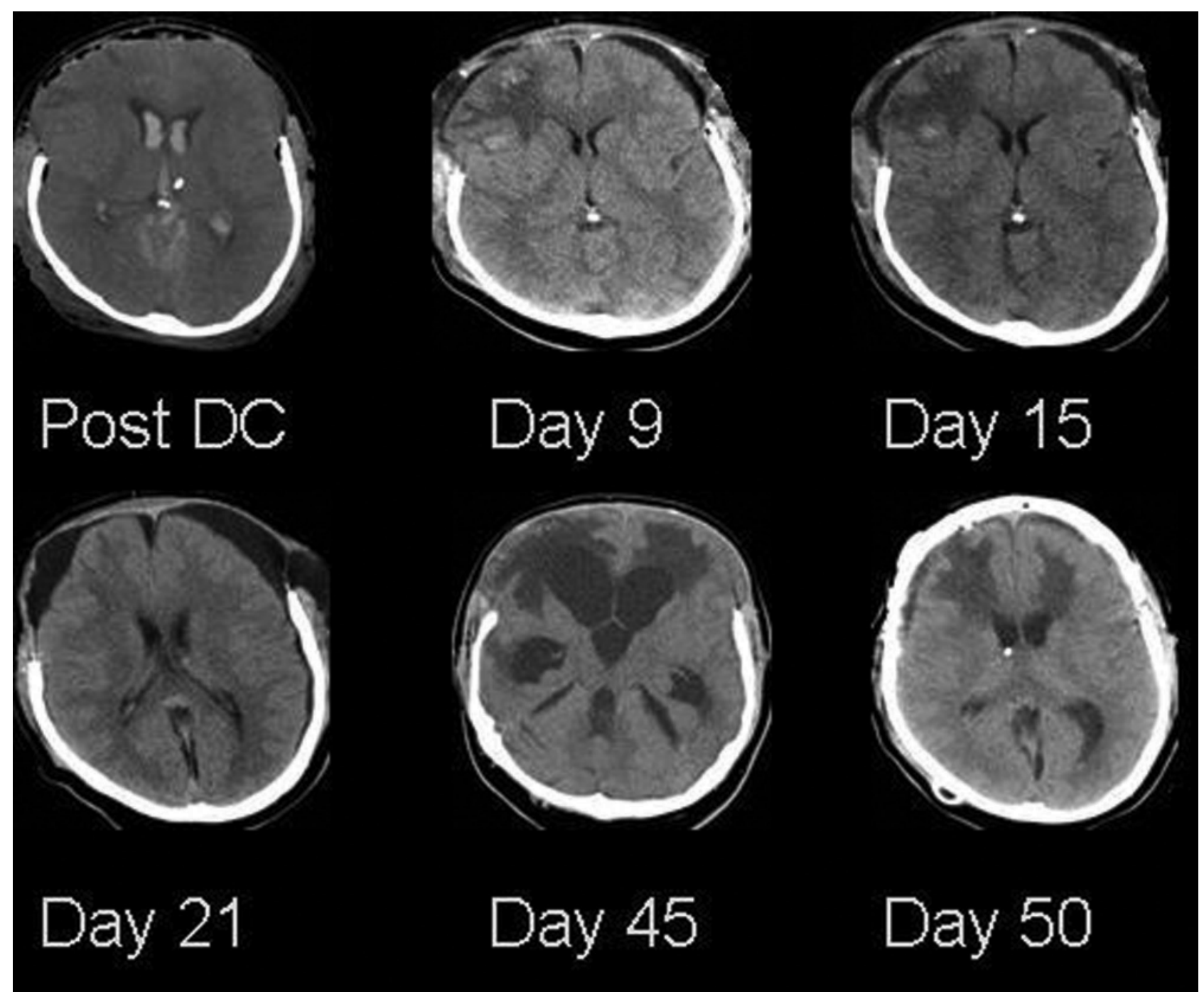

FIG. 3. Computed tomography scans obtained in a 19-year-old man following an MVA, who underwent DC for sustained high ICP $(22.5 \mathrm{~mm} \mathrm{Hg})$ and a right frontal blossomed contusion. Three axial CT scans obtained on Days 9, 15, and 21 showed the gradual appearance of an SDG. The hygroma was absent on a CT scan obtained 24 days later (Day 45), although there was evidence of hydrocephalus. A shunting device was inserted, and autologous cranioplasty was performed 2 days later. Three months after his accident the patient remained severely disabled (GOS Score 3). 


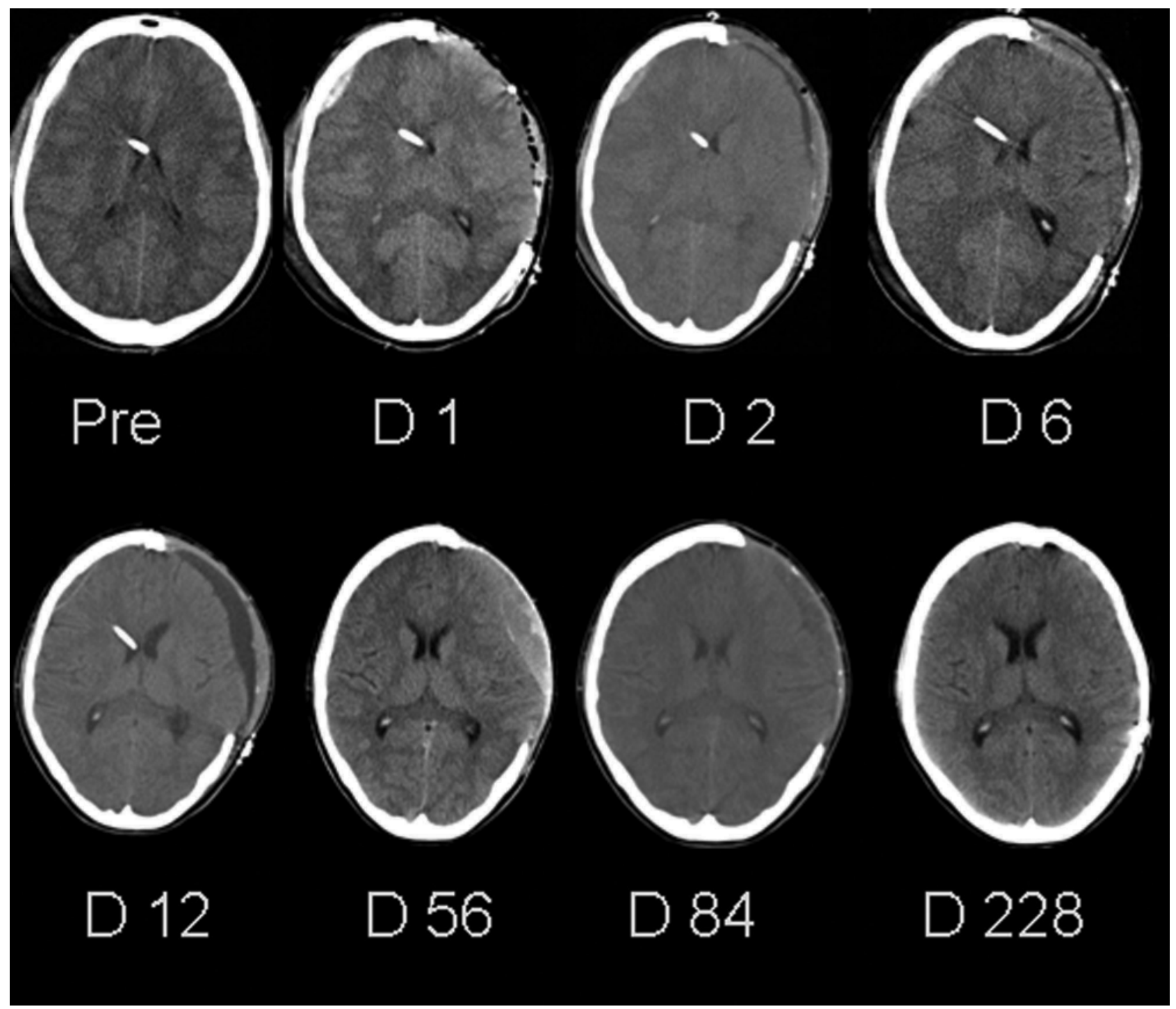

FIG. 4. Three days after her admission, this 16-year-old girl experienced sustained ICP of $31.8 \mathrm{~mm} \mathrm{Hg}$ for which she underwent DC. A follow-up CT scan indicated the first evidence of an SDG on Day 2 (D2) after DC. Although her condition was clinically stable, a head CT obtained on Day 56 (D56) showed evidence of internal bleeding. The SDH gradually disappeared, and she had cranioplasty on Day 228. Thirty-one months after the injury she was asymptomatic with a GOS score of 5.

lar deformation of the third ventricle, enlargement of the lateral ventricles, or evidence of transependymal absorption of CSF. Clinical evidence of a changed mental status or the arrest or slow progression of rehabilitation milestones, as judged by rehabilitation providers, also triggered new CT studies to confirm or disprove the presence of hydrocephalus.

\section{Composition of SDG Fluid}

We checked the composition and cellular content of the SDGs in 5 patients. This fluid was usually bloody and its protein content was high (Table 2). The fluid was collected either in the operating room or at the bedside under aseptic conditions. The volume of the collected fluid was anywhere from 10 to $50 \mathrm{ml}$. One sample cultured enterococci twice after bur hole evacuation of a contralateral SDG on Days 8 and 19 following DC (Fig. 2). The patient in this case was treated with antibiotics. Tapping the SDG collection never resulted in complete resolution of the hygroma.

\section{Conversion to SDHs}

The unexpected appearance of bleeding in an SDG cavity was noted in 3 patients: in 1 on Day 55 of the postDC period and in 2 on Day 57. One SDG with internal bleeding had to be drained (Fig. 4).

\section{Surgical Intervention}

Four patients $(10 \%)$ underwent surgical drainage of an SDG-by twist drill in 1 patient, bur hole in 1, and percutaneous insertion of a draining system in 2 .

\section{Statistical Analysis}

Statistical analysis was performed using JMP soft- 
B. Aarabi et al.

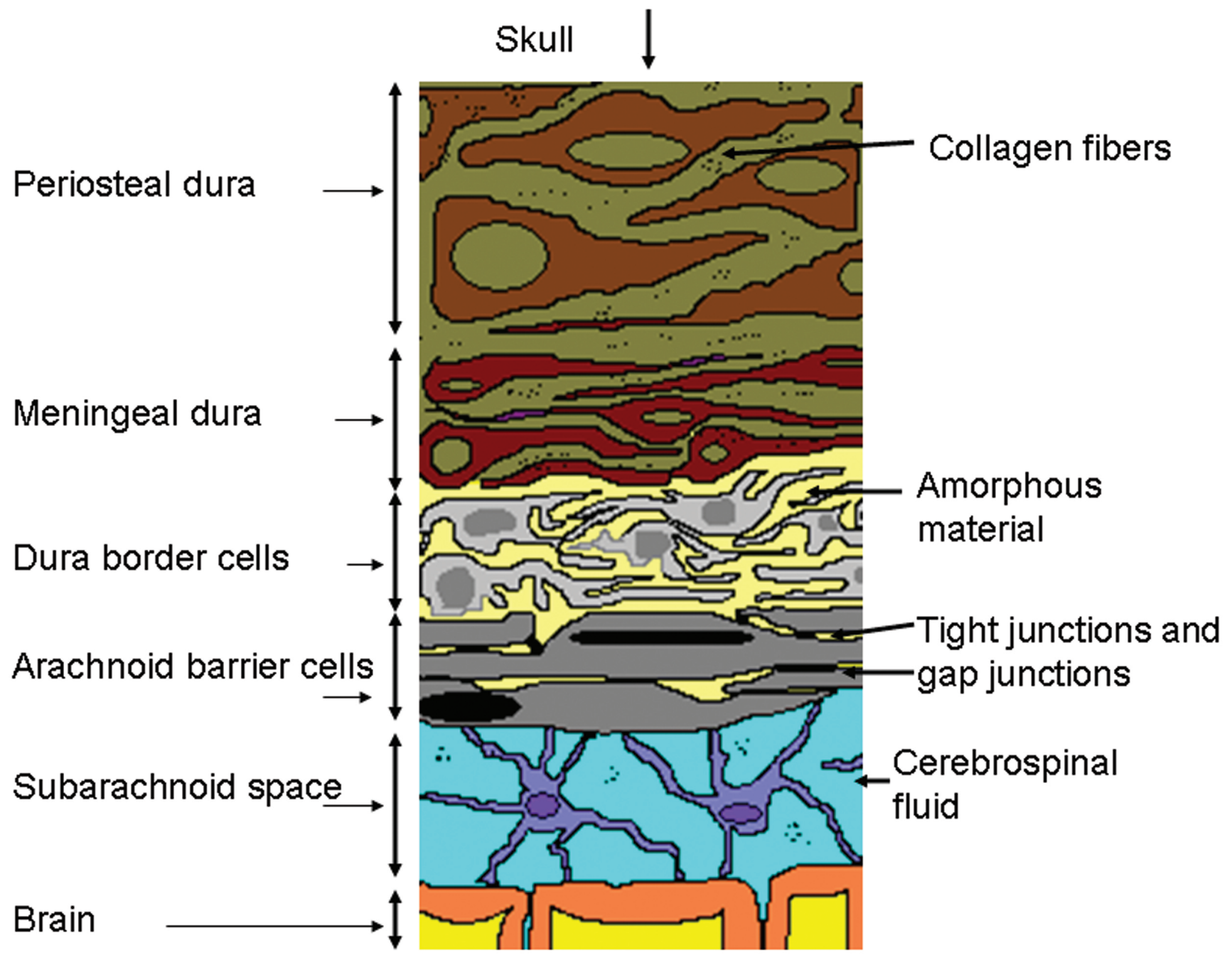

FIG. 5. Schematic representation of dural border cells as observed by electron microscope. ${ }^{25}$

ware (versions 7 and 8, SAS Institute). Two-sided probability values were calculated using the likelihood ratio chi-square for the categorical variables in the 2 groups of patients with or without hygroma. Unpaired t-tests were performed for continuous variables to test for differences in the means between patients with and without hygroma.

\section{Results}

Patient and Injury Factors

Patients with SDGs were close to 4 years younger than those without, but this difference was not statistically significant. Motor vehicle accidents, which were responsible for $66 \%$ of the injuries, were significantly associated with SDG following DC. Among the 45 patients who had been in an MVA, an SDG developed in 31 (69\%) and did not in $14(31 \%)$; this difference was significant $(\mathrm{p}=0.0007)$. In contrast, a fall was the injury mechanism in 10 of 29 patients without a hygroma versus 3 of 39 patients with an SDG, which represented a statistically significant difference between the 2 patient groups $(\mathrm{p}=0.005)$.

\section{Clinical Injury Severity}

There were no significant differences between the 2 patient groups with respect to GCS score, GCS motor score, abnormal pupillary response to light, or injury severity score.

\section{Imaging Profile}

Diffuse injury ${ }^{44}$ occurred in 30 of 39 patients with an SDG compared with 15 of 29 patients without hygromas; this difference was significant $(p=0.0299)$. A compendium of CT characteristics was considered as evidence of diffuse injury: the presence of a mass $<25 \mathrm{ml}$, effacement of gyral patterns, disappearance of the third ventricle, and variable compression or obliteration of the basal cisterns. 


\section{Subdural hygroma following decompressive craniectomy}
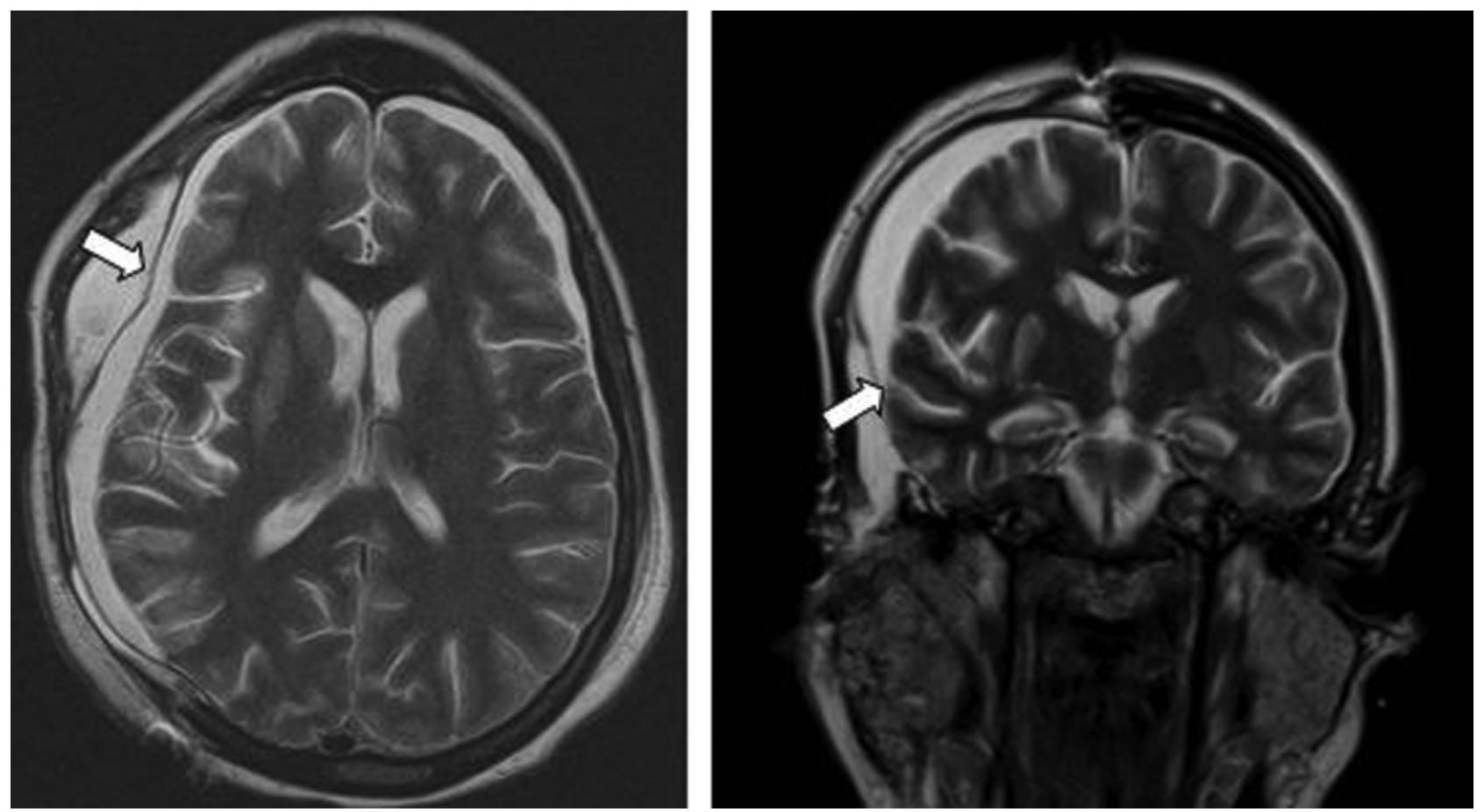

FIG. 6. This 19-year-old woman underwent DC 5 days after her admission for ICP control and CPP management. Axial (left) and coronal (right) T2-weighed MR images obtained 14 days after a traumatic brain injury, indicating an SDG collection over and under the expansive duraplasty (arrows).

Furthermore, $82.7 \%$ of patients with no hygroma-compared with $23.1 \%$ of those with an SDG-had an evacuated mass $(\mathrm{p}=0.0001) .{ }^{44} \mathrm{~A}$ shift of the midline structures $>5 \mathrm{~mm}$ on preoperative $\mathrm{CT}$, compressed or obliterated basal cisterns, and the presence or absence of an intraventricular or subarachnoid hemorrhage were not significant variables in the development of an SDG.

\section{Medical and Surgical Management}

Although Lang et al. ${ }^{38}$ have reported a relationship between increased CPP and the appearance of an SDG, we could not verify that finding in our study. In addition, the timing of a DC did not play a role in the development of an SDG. Hydrocephalus occurred in 13 patients and required CSF diversion; 6 of these patients had a hygroma whereas 7 did not (Table 1).

\section{Patient Outcome}

Although an unfavorable outcome (GOS Score 1-3) was split between the 2 patient groups, there seemed to be an indication that patients with an SDG had a better outcome (GOS Score 4 or 5) than those without. Almost $67 \%$ of the patients with an SDG fared well compared with < $40 \%$ of patients without an SDG who fared well; however, this difference was not a statistically significant finding.

\section{Discussion}

\section{Dynamics of CSF Physiology}

The CSF located in the ventricular system and subarachnoid space constitutes $\sim 150 \mathrm{ml}$ of the $1600 \mathrm{ml}$ de- fined as the volume contained in the intracranial vault. It is a continually produced, absorbed, and circulated fluid providing both mechanical and chemical protection for the brain through the regulation of the CNS chemical environment, the removal of metabolic waste in a role analogous to the peripheral lymphatics, the support/buoyancy of the brain, and the maintenance of ICP in accordance with the Monro-Kellie doctrine. ${ }^{26,59,69}$ The CSF is formed in a diurnal fashion at a rate of $\sim 35 \mathrm{ml} /$ hour or $500 \mathrm{ml} /$ day with maximal production occurring at around 2:00 a.m. and minimal production at around 6:00 p.m. ${ }^{52}$ Located in the lateral, third, and fourth ventricles, the choroid plexus is responsible for $\sim 60-70 \%$ of the daily CSF production, with the remaining fluid generated through a number of mechanisms including the movement of water across parenchymal capillaries, across the ependyma, and via the generation of water from the oxidative metabolism of glucose. . $8,26,59,72^{2}$

\section{Choroid Plexus Anatomy}

The choroid plexus, responsible for the majority of CSF production, consists of a superficial layer made of a single sheet of epithelial cells, supported by a core of connective tissue interspersed with blood vessels of various diameters from small arteries to capillaries to small veins. The epithelial lining of the choroid plexus is a single sheet of polarized cuboidal to columnar cells with a smooth basal side, a more structurally complex luminal side containing numerous microvilli intended to increase the luminal surface area, and tight junctions composed of occludin and claudin found laterally between adjacent cells, all contributing to the formation of the blood-CSF 
barrier. ${ }^{59}$ The blood supply originates from the choroidal arteries, travels through a fenestrated network of capillaries, and ultimately drains into the vein of Galen via the internal cerebral veins at a rate of $\sim 3 \mathrm{ml} / \mathrm{g} / \mathrm{min}, 10$ times that of the brain parenchyma.

\section{Choroidal Production of CSF}

In the simplest terms, the production of CSF at the choroid plexus is the result of the active secretion of $\mathrm{Na}$, $\mathrm{Cl}$, and bicarbonate ions in exchange for $\mathrm{K}$ ions across the luminal surface of the choroidal epithelium to create an osmotic gradient that allows movement of water from the vasculature into the subarachnoid spaces. The primary driving force of CSF secretion is an $\mathrm{Na}^{+} / \mathrm{K}^{+}$-ATPase transporter located on the luminal surface, which actively secretes 3 molecules of $\mathrm{Na}^{+}$in exchange for 2 molecules of $\mathrm{K}^{+}$at the expense of a molecule of ATP hydrolyzed. ${ }^{45,60,78}$ Additional transporters including the ion channel $\mathrm{NKCCl}$, the $\mathrm{K}^{+} / \mathrm{Cl}^{-}$cotransporter $(\mathrm{KCC})$, and several $\mathrm{K}^{+}$-specific channels (Kir7.1, Kv1.1, and Kv1.3) are involved in generating an ionic gradient across the luminal surface.

In contrast to luminal transport mechanisms, basolateral ion movement is not as well understood. Several channels have been proposed to have a role in the movement of $\mathrm{Na}^{+}$and $\mathrm{Cl}^{-}$into cells from the basolateral surface, including $\mathrm{Na}^{+} / \mathrm{H}^{+}$exchangers and an electroneutral $\mathrm{Cl}^{-} /$ $\mathrm{HCO}_{3}{ }^{-}$exchanger, but the work to clarify these processes is ongoing. ${ }^{42,59}$ Intracellularly, the $\mathrm{H}^{+}$and $\mathrm{HCO}_{3}^{-}$needed for these channels are generated by carbonic anhydrase.

The movement of water along the osmotic gradient generated across the CSF barrier, a relatively water-impermeable structure, is facilitated by AQP1, a member of the aquaporin family of water channels that is expressed at both the basolateral and luminal cell surfaces..$^{51,52,54}$

\section{Cerebrospinal Fluid Circulation}

The flow of CSF originates at its sites of production within the ventricles, with the majority thought to be within the lateral ventricles. Cerebrospinal fluid continues through the foramina of Monro into the third ventricle, through the sylvian aqueduct into the fourth ventricle, and subsequently into the cisterna magna via the foramina of Luschka and Magendie. From the cisterna magna, CSF flows caudally into the spinal subarachnoid spaces, rostrally into the basal cisternal spaces (prepontine, interpeduncular, ambient, and suprasellar cisterns), and dorsally into the subarachnoid spaces over the cortical convexities and cerebellum. Movement of the CSF via these pathways is thought to occur primarily through bulk flow with multiple contributory factors generating a current including respiratory variation, pulsatility imparted by the cardiac pressures transduced through the circle of Willis within the basal cisterns, ciliary movement at the surface of the choroid, and production of new CSF itself. ${ }^{12,13,30}$

\section{Absorption of CSF}

Under normal conditions, CSF is maintained at a relatively stable volume that is balanced by the difference between fluid production, as described above, and the return of fluid to the venous circulation. The traditional view of CSF circulation and cycling has been that the major, perhaps sole, site of CSF absorption and return to the venous system is the arachnoid granulation. In actuality, CSF outflow involves both the arachnoid granulations and lymphatic drainage in what has been referred to as the "dual system of CSF drainage." 32 Arachnoid granulations or villi, also called "pacchionian bodies," are small protrusions of the arachnoid membrane through the dura into the venous sinuses. These structures have also been demonstrated in the arachnoid angles of spinal nerves. A hydrostatic pressure gradient in which subarachnoid pressure exceeds venous sinus pressure forces the return of CSF to the venous system. ${ }^{14}$ Interestingly, in the reverse situation, when venous pressures exceed ICP (for example, venous sinus thrombosis), CSF return is inhibited via the arachnoid villi, but reverse flow is not seen. ${ }^{32}$ Electron microscopy studies have shown that the arachnoid cells of these granulations form large vacuoles that appear to simultaneously communicate with the luminal and subarachnoid portions, and thus allowing the movement of water. ${ }^{69}$ As mentioned above, CSF resorption is believed to be facilitated through a lymphatic pathway. It is true that no lymphatic system exists within the CNS, but experimental data from both animals and humans have shown that tracer molecules injected directly into the brain can be found in the perivascular areas of cranial nerves and ultimately within cervical and spinal lymph nodes. Additionally, experimental occlusion of lymphatics draining the head in several animal models has led to increased ICP, suggesting an important role for lymphatic drainage. . $^{7,30,31,35,50}$

\section{Incidence of SDGS}

In patients with a closed-head injury who have not undergone a DC, the reported incidence of SDG varies from 5 to $21 \%$. $5,22,33,39,40,53$ Ohno and colleagues ${ }^{53}$ have reported 43 SDGs (6\%) in 715 patients, and in the Kaufman et al. study ${ }^{33}$ the incidence of an SDG was 38 (4\%) in 881 patients with a closed-head injury. Born and associates ${ }^{5}$ have described 16 patients $(15 \%)$ with SDGs among 109 with blunt traumatic brain injury. The incidence of an SDG following DC for severe head injury is not well documented in the literature. ${ }^{1-3,34,66,76,77}$ In a 2009 study Yang et al. ${ }^{75}$ demonstrated 11 cases $(6.5 \%)$ of contralateral SDGs among 169 patients who had undergone DC for severe head injury. In an earlier study ${ }^{76}$ these same authors documented 23 cases $(21.3 \%)$ of SDGs in 108 patients who had undergone DC for severe head injury. In that study 11 patients had SDG collections ipsilateral and 9 had hygromas contralateral to the side of the DC; 3 of the 23 SDG collections were interhemispheric. Contralateral hygromas have also been documented in case reports by Kilincer et al. ${ }^{34}$ and Su et al. ${ }^{66}$ In the present study we saw that SDGs developed in $39(57.4 \%)$ of 68 patients who had survived $>1$ month after traumatic brain injury and DC. ${ }^{1-3}$

\section{Pathogenesis and Evolution of SDG}

Traumatic Shearing Stress. Detailed electron microscopy studies by Haines et al. ${ }^{25}$ and Schachenmayr 


\section{Subdural hygroma following decompressive craniectomy}

and Friede ${ }^{63}$ have indicated that there is no dead space between the dura and arachnoid layers. The interface between the dura mater and subarachnoid space is made of an interface layer composed of an arachnoid barrier layer and a dural border cell layer (Fig. 5 upper). Whereas a significant number of collagen fibers bond the cellular structure of periosteal and meningeal dura, the dural border cell layer contains very little collagen, and instead, cellular elements are loosely held together by an amorphous material prone to disruption by physical stress..$^{25,63}$ Protecting the subarachnoid space and its trabeculae is the arachnoid barrier cell layer in which the cellular elements are tightly packed together by desmosomes, tight junctions, and gap junctions. ${ }^{25,63}$ Shearing stress generated by kinetic energy can tear arachnoid barrier cells and damage the integrity of the arachnoid-dura interface layer. ${ }^{25}$ In our study patients who had been in MVAs were significantly more prone to SDGs $(\mathrm{p}<0.0007)$ than were those who had fallen. It is quite likely that the former patients had a significantly more damaged arachnoiddura interface layer during sudden exposure to a highly dynamic kinetic energy. Supporting this notion are the reported cases of SDGs contralateral to the side of the DC. ${ }^{66,75,76}$ In our series of 39 cases with SDGs, 3 hygromas were contralateral to the side of DC (Fig. 2).

Iatrogenic Surgical Disruption of the ArachnoidDura Interface. Another mechanism contributing to the egress of CSF into the subdural space and the formation of an SDG in the context of a DC is iatrogenic damage to the arachnoid-dura interface layer by the neurosurgeon during expansive duraplasty (Fig. 5 lower). Up to $90 \%$ of hygromas in our study were ipsilateral to the side of craniectomy. This finding is contrary to the laterality of SDGs in closed-head injury, which is almost equally distributed on the right and left sides. Koizumi et al. ${ }^{36}$ and St John and Dila ${ }^{64}$ have documented 63 cases of SDGs: 32 bilateral, 12 on the right side, and 19 on the left side.

Evolution of an SDG. The accumulation of CSF in the subdural space in closed-head injury, as reported by Koizumi et al., ${ }^{37}$ peaks at 20-30 days. The evolution of an SDG following DC has never been systematically evaluated. In our analysis an SDG could be seen even on the 2nd postoperative day (Fig. 4). When studied in the aggregate, the fluid collections increased in size for up to 4 weeks post-DC and gradually tapered, but lingered for up to 4 months after surgery (Fig. 1). Once in the subdural space, an SDG may exit the suture line of an expansive duraplasty and collect underneath the skin (Fig. 6).

Hydrocephalus. An added complexity to the pathogenesis of these hygromas includes the appearance of hydrocephalus after the complete disappearance of SDGs in 3 patients, pointing to possible difficulties with the dynamics of CSF circulation in patients with DC (Fig. 3). In our study hydrocephalus and the need for surgical CSF diversion was noted at Weeks 5-8, 17, and 22 after DC in 6 patients.

Hemorrhagic Conversion. Subdural hygroma fluid noted in severe head injury and DC is usually xanthochromic, contains a varied number of red blood cells, and is high in protein. ${ }^{15,39,40,61,62,65,71,73}$ Hygroma fluid aspirated in 5 patients at the Shock Trauma Center contained high numbers of red blood cells and high protein levels (Table 2). Evidence indicates that this high-protein, highly xanthochromic fluid induces an inflammatory response in the subdural space, predisposing to neomembrane formation with fragile and leaky capillaries. ${ }^{21,61,62}$ The maturation of a hygroma neomembrane, containing fragile and leaky capillaries superimposed on stretched parasagittal veins, ${ }^{55}$ may make hygromas susceptible to internal bleeding and foster the conversion of a benign SDG into a chronic SDH. ${ }^{19,21,37,39,43,48,53,56,57}$ Between 6 and $32 \%$ of SDGs convert into chronic SDHs. ${ }^{21}$ In the Liu et al. series ${ }^{43}$ conversion happened from Days 22-100 after traumatic brain injury. In the Ohno et al. study ${ }^{53} 20$ of 43 patients with hygromas eventually showed evidence of bleeding inside the collection. In the Koizumi et al. series $^{37}$ hygromas in 4 patients converted to SDHs on Days $50,70,71$, and 72 after their trauma. The hygromas in 3 patients in our study converted into chronic SDHs on Days 55, 57, and 57 post-DC (Fig. 4).

\section{Management and Outcome}

The visualization of SDGs on imaging studies does not suggest immediate intervention. Contralateral SDGs are more likely to induce a global decline in cognition and consciousness. Yang et al. ${ }^{75}$ have reported on 11 patients with contralateral SDGs among 169 who had undergone DC; the hygroma spontaneously resolved in 7 patients and had to be drained in 4 . Kilincer et al. ${ }^{34}$ have described a 56-year-old man who had undergone a DC for malignant stroke and in whom a contralateral SDG later developed. The SDG in this patient was evacuated first by drainage and subsequently by subdural-peritoneal shunting. Similarly, Su et al. ${ }^{66}$ have described a 63-year-old man with a posttraumatic evacuated mass who had undergone a DC and whose level of consciousness globally declined due to a contralateral SDG and significant shift of the midline structures. This patient responded well to simple drainage of the hygroma and was discharged symptom free 1 week later. There seems to be a tendency for contralateral SDGs to cause more symptoms. ${ }^{34,66,75}$ In our study 4 patients underwent drainage of the SDG. Three (8\%) of 39 patients with hygromas had evidence of mass effect, that is, a shift in the midline structures $>5 \mathrm{~mm}$ : 1 of 36 patients with an ipsilateral and 2 of 3 patients with contralateral SDGs. All 3 patients needed subdural drains to reverse the existing shift (1 bur hole, 1 twist drill, and 1 percutaneous insertion of a draining system; Fig. 2). Two of 3 patients whose images had demonstrated a shift of midline structures (5.9 and $6.8 \mathrm{~mm}$ ) had unchanged GCS scores following drainage of the subdural fluid: GCS Score 8 (Motor Score 3 ) in 1 patient and GCS Score 14 in the other. In 2 patients with clinical neurological worsening, the GCS score improved after drainage of the SDGs. One patient had a sudden decrease in his GCS motor score (from 6 to 5), which improved after the insertion of a percutaneous drain for an ipsilateral hygroma. Dysautonomic changes in another patient's vital signs occurred (heart rate increased to 115 bpm and temperature increased to $102^{\circ} \mathrm{F}$ ), and he became obtunded. Computed tomography studies in this patient 
revealed a 20.2-mm shift due to a contralateral hygroma. This patient underwent bur hole evacuation of this SDG twice. His neurological status improved immediately after surgery (Fig. 2). The overall prognosis for an SDG was better in patients with diffuse injury than in patients with an evacuated mass, which may be simply a reflection of the fact that the prognosis of DC in our 2 published series was better in patients with diffuse injuries than in those with evacuated masses and possibly had nothing to do with the presence or absence of an SDG. ${ }^{2,3}$

\section{Conclusions}

An SDG developed in almost $57 \%$ of the patients who had undergone DC and survived the 1st month of hospitalization. ${ }^{2,3}$ Although 3 patients harbored a contralateral SDG, $36(92 \%)$ of 39 patients had an SDG ipsilateral to the side of DC.

Based on electron microscopy studies, ${ }^{25,63}$ necropsy findings, ${ }^{15,49}$ and the entrance of contrast material into the hygroma cavity after contrast cisternography, ${ }^{46}$ it is hypothesized that injury to the arachnoid-dura interface layer is the central pathology in SDGs. Spillage of the CSF into the subdural space peaked at 3-4 weeks after DC, and this pathological process gradually ceased from 14-17 weeks postoperatively. There is evidence that the proximity of the hygroma fluid with the dura upregulates excitatory cytokine synthesis and neomembrane formation. It is likely that expansion of the hygroma fluid will put undue stress on the walls of parasagittal veins, resulting in fresh bleeding into the hygroma cavity. ${ }^{55}$ In addition, bleeding from the neomembrane capillaries may contribute to the possible conversion of a benign-looking hygroma into a chronic SDH.

In our experience, high dynamic accidents and diffuse traumatic brain injuries were risk factors for an SDG following DC.

The majority of hygromas-regardless of their size or internal bleeding - gradually disappeared without surgical management. Contralateral hygromas needed more aggressive treatment because of their tendency to cause midline shift. A variety of surgical management strategies have been used for the evacuation of SDGs including bur hole evacuation, bedside subdural drains, and craniotomy. $37,40,64,65,75,76$

\section{Disclaimer}

The authors report no conflict of interest concerning the materials or methods used in this study or the findings specified in this paper.

\section{Reference}

1. Aarabi B: Decompressive craniectomy for intracranial hypertension. Presented at the 26th Annual National Neurotrauma Symposium held in Orlando, Florida, July 27-30, 2008

2. Aarabi B, Hesdorffer DC, Simard JM, Ahn ES, Aresco C, Eisenberg HM, et al: Comparative study of decompressive craniectomy following mass lesion evacuation in severe head injury. Neurosurgery 64:927-940, 2009

3. Aarabi B, Hesdorffer DC, Ahn ES, Aresco C, Scalea TM, Eisenberg HM: Outcome following decompressive craniec- tomy for malignant swelling due to severe head injury. J Neurosurg 104:469-479, 2006

4. Arnason O, Jakobsson KE, Lindgren S: Extracerebral nonhaemorrhagic expansive complications of intracranial surgery. Acta Neurochir (Wien) 67:231-238, 1983

5. Born JD, Hans P, Flandroy P, Milbouw G, Bonnal J: [Incidence and treatment of subdural hygroma in severe head injuries] Acta Anaesthesiol Belg 84:174-182, 1984 (Fr)

6. Borzone M, Capuzzo T, Perria C, Rivano C, Tercero E: Traumatic subdural hygromas: a report of 70 surgically treated cases. J Neurosurg Sci 27:161-165, 1983

7. Boulton M, Flessner M, Armstrong D, Hay J, Johnston M: Lymphatic drainage of the CNS: effects of lymphatic diversion/ligation on CSF protein transport to plasma. Am J Physiol 272:R1613-R1619, 1997

8. Broadwell RD, Sofroniew MV: Serum proteins bypass the blood-brain fluid barriers for extracellular entry to the central nervous system. Exp Neurol 120:245-263, 1993

9. Cohen I: Chronic subdural accumulations of cerebrospinal fluid after cranial trauma. Arch Neurol Psychiatry 18:709723,1927

10. Compagnone C, Murray GD, Teasdale GM, Maas AI, Esposito $\mathrm{D}$, Princi $\mathrm{P}$, et al: The management of patients with intradural post-traumatic mass lesions: a multicenter survey of current approaches to surgical management in 729 patients coordinated by the European Brain Injury Consortium. Neurosurgery 57:1183-1192, 2005

11. Coplin WM, Cullen NK, Policherla PN, Vinas FC, Wilseck JM, Zafonte RD, et al: Safety and feasibility of craniectomy with duraplasty as the initial surgical intervention for severe traumatic brain injury. J Trauma 50:1050-1059, 2001

12. Cserr HF, Cooper DN, Milhorat TH: Flow of cerebral interstitial fluid as indicated by the removal of extracellular markers from rat caudate nucleus. Exp Eye Res 25 (Suppl):S461S473, 1977

13. Cserr HF, Ostrach LH: Bulk flow of interstitial fluid after intracranial injection of blue dextran 2000. Exp Neurol 45:5060, 1974

14. d'Avella D, Greenberg RP, Mingrino S, Scanarini M, Pardatscher K: Alterations in ventricular size and intracranial pressure caused by sagittal sinus pathology in man. J Neurosurg 53:656-661, 1980

15. Da Costa DG, Adson AW: Subdural hygroma. Arch Surg 43:559-567, 1941

16. Dandy WE: Chronic subdural hydroma and serous meningitis (pachymeningitis serosa; localized external hydrocephalus), in Lewis D (ed): Practice of Surgery. Hagerstown, Maryland: WF Prior, 1932, pp 306-309

17. Dandy WE: Chronic subdural hydroma and serous meningitis (pachymeningitis serosa; localized external hydrocephalus), in Lewis D (ed): Practice of Surgery. Hagerstown, Maryland: WF Prior, 1955, pp 291-293

18. de Rougemont: Ames A III, Nesbett FB, Hofmann HF. Fluid formed by choroid plexus; a technique for its collection and a comparison of its electrolyte composition with serum and cisternal fluids. J Neurophysiol 23:485-495, 1960

19. Deltour P, Lemmerling M, Bauters W, Siau B, Kunnen M: Posttraumatic subdural hygroma: CT findings and differential diagnosis. JBR-BTR 82:155-156, 1999

20. Endtz LJ: Post-traumatic hygroma in the eighteenth century: described by Thomas Schwencke. Surg Neurol 10:305-307, 1978

21. Feng JF, Jiang JY, Bao YH, Liang YM, Pan YH: Traumatic subdural effusion evolves into chronic subdural hematoma: two stages of the same inflammatory reaction? Med Hypotheses 70:1147-1149, 2008

22. French BN, Cobb CA III, Corkill G, Youmans Jr: Delayed evolution of posttraumatic subdural hygroma. Surg Neurol 9:145-148, 1978 


\section{Subdural hygroma following decompressive craniectomy}

23. Gaab MR, Rittierodt M, Lorenz M, Heissler HE: Traumatic brain swelling and operative decompression: a prospective investigation. Acta Neurochir Suppl (Wien) 51:326-328, 1990

24. Gebel JM, Sila CA, Sloan MA, Granger CB, Weisenberger JP, Green CL, et al: Comparison of the $\mathrm{ABC} / 2$ estimation technique to computer-assisted volumetric analysis of intraparenchymal and subdural hematomas complicating the GUSTO-1 trial. Stroke 29:1799-1801, 1999

25. Haines DE, Harkey HL, al-Mefty O: The "subdural" space: a new look at an outdated concept. Neurosurgery 32:111-120, 1993

26. Han CY, Backous DD: Basic principles of cerebrospinal fluid metabolism and intracranial pressure homeostasis. Otolaryngol Clin North Am 38:569-576, 2005

27. Hasegawa M, Yamashima T, Yamashita J, Suzuki M, Shimada S: Traumatic subdural hygroma: pathology and meningeal enhancement on magnetic resonance imaging. Neurosurgery 31:580-585, 1992

28. Hoff J, Bates E, Barnes B, Glickman M, Margolis T: Traumatic subdural hygroma. J Trauma 13:870-876, 1973

29. Jiang JY, Xu W, Li WP, Xu WH, Zhang J, Bao YH, et al: Efficacy of standard trauma craniectomy for refractory intracranial hypertension with severe traumatic brain injury: a multicenter, prospective, randomized controlled study. J Neurotrauma 22:623-628, 2005

30. Johnston I, Teo C: Disorders of CSF hydrodynamics. Childs Nerv Syst 16:776-799, 2000

31. Johnston M, Zakharov A, Koh L, Armstrong D: Subarachnoid injection of Microfil reveals connections between cerebrospinal fluid and nasal lymphatics in the non-human primate. Neuropathol Appl Neurobiol 31:632-640, 2005

32. Kapoor KG, Katz SE, Grzybowski DM, Lubow M: Cerebrospinal fluid outflow: an evolving perspective. Brain Res Bull 77:327-334, 2008

33. Kaufman HH, Childs TL, Wagner KA, Bernstein DP, Karon M, Khalid M, et al: Post-traumatic subdural hygromas: observations concerning a surgical enigma. Acta Neurochir (Wien) 72:197-209, 1984

34. Kilincer C, Simsek O, Hamamcioglu MK, Hicdonmez T, Cobanoglu S: Contralateral subdural effusion after aneurysm surgery and decompressive craniectomy: case report and review of the literature. Clin Neurol Neurosurg 107:412-416, 2005

35. Koh L, Zakharov A, Nagra G, Armstrong D, Friendship R, Johnston M: Development of cerebrospinal fluid absorption sites in the pig and rat: connections between the subarachnoid space and lymphatic vessels in the olfactory turbinates. Anat Embryol (Berl) 211:335-344, 2006

36. Koizumi H, Fukamachi A, Nukui H: Postoperative subdural fluid collections in neurosurgery. Surg Neurol 27:147-153, 1987

37. Koizumi H, Fukamachi A, Wakao T, Tasaki T, Nagaseki Y, Yanai Y: [Traumatic subdural hygromas in adults-on the possibility of development of chronic subdural hematoma (author's transl).] Neurol Med Chir (Tokyo) 21:397-406, 1981

38. Lang JK, Ludwig HC, Mursch K, Zimmerer B, Markakis E: Elevated cerebral perfusion pressure and low colloid osmotic pressure as a risk factor for subdural space-occupying hygromas? Surg Neurol 52:630-637, 1999

39. Lee KS, Bae WK, Bae HG, Yun IG: The fate of traumatic subdural hygroma in serial computed tomographic scans. J Korean Med Sci 15:560-568, 2000

40. Lee KS, Bae WK, Park YT, Yun IG: The pathogenesis and fate of traumatic subdural hygroma. Br J Neurosurg 8:551558,1994

41. Li G, Wen L, Yang XF, Zheng XJ, Zhan RY, Liu WG: Efficacy of large decompressive craniectomy in severe traumatic brain injury. Chin J Traumatol 11:253-256, 2008
42. Lindsey AE, Schneider K, Simmons DM, Baron R, Lee BS, Kopito RR: Functional expression and subcellular localization of an anion exchanger cloned from choroid plexus. Proc Natl Acad Sci U S A 87:5278-5282, 1990

43. Liu YG, Xu CJ, Zhu SG, Jiang YQ, Li G, Li XG, et al: Traumatic subdural hydroma developing into chronic subdural hematoma. Chin J Traumatol 7:188-190, 2004

44. Marshall LF, Marshall SB, Klauber MR, et al: A new classification of head injury based on computerized tomography. J Neurosurg 75(Suppl):S14-S20, 1991

45. Masuzawa T, Ohta T, Kawamura M, Nakahara N, Sato F: Immunohistochemical localization of Na+, K+-ATPase in the choroid plexus. Brain Res 302:357-362, 1984

46. Mori K, Maeda M: Delayed magnetic resonance imaging with GdD-DTPA differentiates subdural hygroma and subdural effusion. Surg Neurol 53:303-310, 2000

47. Munch E, Horn P, Schurer L, Piepgras A, Paul T, Schmiedek P: Management of severe traumatic brain injury by decompressive craniectomy. Neurosurgery 47:315-322, 2000

48. Murata K: Chronic subdural hematoma may be preceded by persistent traumatic subdural effusion. Neurol Med Chir (Tokyo) 33:691-696, 1993

49. Naffziger HC: Subdural fluid accumulation following head injury. JAMA 82:1751-1752, 1924

50. Nagra G, Koh L, Zakharov A, Armstrong D, Johnston M: Quantification of cerebrospinal fluid transport across the cribriform plate into lymphatics in rats. Am J Physiol Regul Integr Comp Physiol 291:R1383-R1389, 2006

51. Nielsen S, Smith BL, Christensen EI, Agre P: Distribution of the aquaporin CHIP in secretory and resorptive epithelia and capillary endothelia. Proc Natl Acad Sci U S A 90:72757279,1993

52. Nilsson C, Ståhlberg F, Thomsen C, Henriksen O, Herning M, Owman C: Circadian variation in human cerebrospinal fluid production measured by magnetic resonance imaging. Circadian variation in human cerebrospinal fluid production measured by magnetic resonance imaging. Am J Physiol 262:R20-R24, 1992

53. Ohno K, Suzuki R, Masaoka H, Matsushima Y, Inaba Y, Monma S: Chronic subdural haematoma preceded by persistent traumatic subdural fluid collection. J Neurol Neurosurg Psychiatry 50:1694-1697, 1987

54. Oshio K, Watanabe H, Song Y, Verkman AS, Manley GT: Reduced cerebrospinal fluid production and intracranial pressure in mice lacking choroid plexus water channel Aquaporin-1. FASEB J 19:76-78, 2005

55. Papasian NC, Frim DM: A theoretical model of benign external hydrocephalus that predicts a predisposition towards extra-axial hemorrhage after minor head trauma. Pediatr Neurosurg 33:188-193, 2000

56. Park CK, Choi KH, Kim MC, Kang JK, Choi CR: Spontaneous evolution of posttraumatic subdural hygroma into chronic subdural haematoma. Acta Neurochir (Wien) 127:41-47, 1994

57. Park SH, Lee SH, Park J, Hwang JH, Hwang SK, Hamm IS: Chronic subdural hematoma preceded by traumatic subdural hygroma. J Clin Neurosci 15:868-872, 2008

58. Polin RS, Shaffrey ME, Bogaev CA, Tisdale N, Germanson $\mathrm{T}$, Bocchicchio B, et al: Decompressive bifrontal craniectomy in the treatment of severe refractory posttraumatic cerebral edema. Neurosurgery 41:84-92, 1997

59. Praetorius J: Water and solute secretion by the choroid plexus. Pflugers Arch 454:1-18, 2007

60. Praetorius J, Nielsen S: Distribution of sodium transporters and aquaporin-1 in the human choroid plexus. Am J Physiol Cell Physiol 291:C59-C67, 2006

61. Rabe EF, Flynn RE, Dodge PR: A study of subdural effusions in an infant. With particular reference to the mechanisms of their persistence. Neurology 12:79-92, 1962 
62. Rabe EF, Flynn RE, Dodge PR: Subdural collections of fluid in infants and children. A study of 62 patients with special reference to factors influencing prognosis and the efficacy of various forms of therapy. Neurology 18:559-570, 1968

63. Schachenmayr W, Friede RL: The origin of subdural neomembranes. I. Fine structure of the dura-arachnoid interface in man. Am J Pathol 92:53-68, 1978

64. St John JN, Dila C: Traumatic subdural hygroma in adults. Neurosurgery 9:621-626, 1981

65. Stone JL, Lang RG, Sugar O, Moody RA: Traumatic subdural hygroma. Neurosurgery 8:542-570, 1981

66. Su FW, Ho JT, Wang HC: Acute contralateral subdural hygroma following craniectomy. J Clin Neurosci 15:305-307, 2008

67. Sucu HK, Gokmen M, Gelal F: The value of XYZ/2 technique compared with computer-assisted volumetric analysis to estimate the volume of chronic subdural hematoma. Stroke 36:998-1000, 2005

68. Timofeev I, Kirkpatrick PJ, Corteen E, Hiler M, Czosnyka M, Menon DK, et al: Decompressive craniectomy in traumatic brain injury: outcome following protocol-driven therapy. Acta Neurochir Suppl (Wien) 96:11-16, 2006

69. Tripathi BJ, Tripathi RC: Vacuolar transcellular channels as a drainage pathway for cerebrospinal fluid. J Physiol 239:195206, 1974

70. Ucar T, Akyuz M, Kazan S, Tuncer R: Role of decompressive surgery in the management of severe head injuries: prognostic factors and patient selection. J Neurotrauma 22:1311-1318, 2005

71. Weir B: Oncotic pressure of subdural fluids. J Neurosurg 53:512-515, 1980
72. Welch K: Secretion of cerebrospinal fluid by choroid plexus of the rabbit. Am J Physiol 205:617-624, 1963

73. Wetterling T, Demierre B, Rama B, Nekic M: Protein analysis of subdural hygroma fluid. Acta Neurochir (Wien) 91:79-82, 1988

74. Whitfield PC, Patel H, Hutchinson PJ, Czosnyka M, Parry D, Menon D, et al: Bifrontal decompressive craniectomy in the management of posttraumatic intracranial hypertension. $\mathbf{B r} \mathbf{J}$ Neurosurg 15:500-507, 2001

75. Yang XF, Wen L, Li G, Zhan RY, Ma L, Liu WG: Contralateral subdural effusion secondary to decompressive craniectomy performed in patients with severe traumatic brain injury: incidence, clinical presentations, treatment and outcome. Med Princ Pract 18:16-20, 2009

76. Yang XF, Wen L, Shen F, Li G, Lou R, Liu WG, et al: Surgical complications secondary to decompressive craniectomy in patients with a head injury: a series of 108 consecutive cases. Acta Neurochir (Wien) 150:1241-1247, 2008

77. Yoo DS, Kim DS, Cho KS, Huh PW, Park CK, Kang JK: Ventricular pressure monitoring during bilateral decompression with dural expansion. J Neurosurg 91:953-959, 1999

78. Zeuthen T, Wright EM: An electrogenic $\mathrm{Na}^{+} / \mathrm{K}^{+}$pump in the choroid plexus. Biochim Biophys Acta 511:517-522, 1978

Manuscript submitted February 5, 2009.

Accepted March 30, 2009.

Address correspondence to: Bizhan Aarabi, M.D., F.R.C.S.C., Department of Neurosurgery, University of Maryland School of Medicine, 22 South Greene Street, Suite S-12-D, Baltimore, Maryland 21201. email: baarabi@smail.umaryland.edu. 